\title{
Bur open Evidence-based commissioning in the English NHS: who uses which sources of evidence? A survey 2010/2011
}

\author{
Aileen Clarke, ${ }^{1}$ Sian Taylor-Phillips, ${ }^{1}$ Jacky Swan, ${ }^{2}$ Emmanouil Gkeredakis, ${ }^{2}$ \\ Penny Mills, ${ }^{1}$ John Powell, ${ }^{1}$ Davide Nicolini, ${ }^{2}$ Claudia Roginski, ${ }^{3}$ Harry Scarbrough, ${ }^{2}$ \\ Amy Grove ${ }^{1}$
}

To cite: Clarke A, TaylorPhillips S, Swan J, et al. Evidence-based commissioning in the English NHS: who uses which sources of evidence? A survey 2010/2011. BMJ Open 2013:3:e002714. doi:10.1136/bmjopen-2013002714

- Prepublication history and additional material for this paper are available online. To view these files please visit the journal online (http://dx.doi.org/10.1136/ bmjopen-2013-002714).

Received 11 February 2013 Revised 25 March 2013 Accepted 12 April 2013

This final article is available for use under the terms of the Creative Commons Attribution Non-Commercial 2.0 Licence; see http://bmjopen.bmj.com

\footnotetext{
${ }^{1}$ Division of Health Sciences, Warwick Medical School, University of Warwick, Coventry, UK

${ }^{2}$ Innovation, Knowledge, and Organizational Networks Research Centre, Warwick Business School, University of Warwick, Coventry, UK ${ }^{3}$ NHS South Warwickshire Clinical Commissioning Group, Warwickshire, UK
}

Correspondence to Dr Aileen Clarke; aileen.clarke@warwick.ac.uk

\section{ABSTRACT}

Objectives: To investigate types of evidence used by healthcare commissioners when making decisions and whether decisions were influenced by commissioners' experience, personal characteristics or role at work.

Design: Cross-sectional survey of 345 National Health Service (NHS) staff members.

Setting: The study was conducted across 11 English Primary Care Trusts between 2010 and 2011.

Participants: A total of 440 staff involved in commissioning decisions and employed at NHS band 7 or above were invited to participate in the study. Of those, $345(78 \%)$ completed all or a part of the survey. Main outcome measures: Participants were asked to rate how important different sources of evidence (empirical or practical) were in a recent decision that had been made. Backwards stepwise logistic regression analyses were undertaken to assess the contributions of age, gender and professional background, as well as the years of experience in NHS commissioning, pay grade and work role.

Results: The extent to which empirical evidence was used for commissioning decisions in the NHS varied according to the professional background. Only $50 \%$ of respondents stated that clinical guidelines and cost-effectiveness evidence were important for healthcare decisions. Respondents were more likely to report use of empirical evidence if they worked in Public Health in comparison to other departments $(p<0.0005$, commissioning and contracts $\mathrm{OR} 0.32,95 \% \mathrm{Cl} \quad 0.18$ to 0.57 , finance $\mathrm{OR} 0.19,95 \% \mathrm{Cl} 0.05$ to 0.78 , other departments $\mathrm{OR} 0.35,95 \% \mathrm{Cl} 0.17$ to 0.71 ) or if they were female (OR $1.895 \% \mathrm{Cl} 1.01$ to 3.1 ) rather than male. Respondents were more likely to report use of practical evidence if they were more senior within the organisation (pay grade $8 \mathrm{~b}$ or higher $\mathrm{OR} 2.7,95 \% \mathrm{Cl} 1.4$ to $5.3, p=0.004$ in comparison to lower pay grades). Conclusions: Those trained in Public Health appeared more likely to use external empirical evidence while those at higher pay scales were more likely to use practical evidence when making commissioning decisions. Clearly, National Institute for Clinical Excellence (NICE) guidance and government publications (eg, National Service Frameworks) are important for decision-making, but practical sources of evidence such as local intelligence, benchmarking data and expert advice are also influential.

\section{ARTICLE SUMMARY}

\section{Article focus}

- This paper investigates the types of evidence (empirical or practical) used to make commissioning decisions in Primary Care Trusts (PCTs) in England.

Key messages

- The extent to which empirical evidence is used for commissioning decisions in the National Health Service (NHS) varies according to the professional background.

- Those trained in Public Health and working in commissioning were more likely to report using empirical evidence; senior commissioners were more likely to use practical local evidence.

- Although National Institute for Health and Clinical Excellence guidance and government publications are important for decision-making, the influence of local intelligence, benchmarking data and expert advice cannot be ignored.

Strengths and limitations of this study

- This is a nationwide study of 345 representative commissioning staff in the NHS from 11 PCTs in England with a high response rate $(78 \%)$.

- It represents an important resource for those designing and undertaking commissioning decision-making with clear implications for an issue under significant flux in the NHS due to the introduction of Clinical Commissioning Groups.

- The study would benefit from corroboration by further research using a prospective design to follow individual decisions through commissioning processes.Variation exists in the sources of evidence used for decision-making in commissioning. Professional background, gender and employment status (seniority) had a significant impact on the choice of evidence used for decision-making in NHS Primary Care Trusts.

New Clinical Commissioning Groups will need a variety of different evidence sources and expert involvement to ensure that effective decisions are made for their populations. 


\section{INTRODUCTION}

In England, local healthcare commissioners plan, fund and review health service spending to ensure that sufficient services are available for the defined populations for whom they are responsible. Until recently, commissioning departments were located within Primary Care Trusts (PCTs). ${ }^{1}$ From 1 April 2013, PCTs in England are being abolished and responsibility for commissioning health services is moving to newly formed Clinical Commissioning Groups (CCGs). There are currently 229 planned CCGs who will have responsibility for commissioning services for their local populations. ${ }^{1}$

Commissioning is a complex process undertaken by individuals from a variety of professional backgrounds and disciplines, including medicine, public health, nursing, the allied health professions, finance, accounting, contracting and business studies. ${ }^{2}$ Commissioners must take into account a number of factors such as local need, availability of resources and relevant available information and evidence.

Little is known about how personal characteristics such as employment status and professional background can influence the attitudes and practices of individuals responsible for making healthcare commissioning decisions. Research on evidence use suggests that evidence is defined in various ways and is used differently by the individuals involved. ${ }^{3-5}$ This difference in use is even more clear when evidence requires assimilation in order to be used in practice, ${ }^{6-8}$ and has implications for the creation and composition of CGGs in National Health Service (NHS) in England.

The purpose of this research was to examine the types of evidence local commissioners of health services used in practice during their own recent decision-making processes and variations in this in relation to the characteristics, roles, professional background and experience of the decision-maker.

\section{METHODS}

\section{Survey development}

A cross-sectional questionnaire survey of commissioners working in PCTs in England was conducted. Topic areas and questions were derived from published surveys, literature reviews and our own case study evaluation of commissioning processes in four PCT sites ${ }^{9}$ (see online supplementary appendix 1 for the survey). Prepiloting and piloting of the questionnaire were conducted with purposive samples of participants drawn from local NHS organisations and results were used to develop and refine the questionnaire and the process of administration.

Participants were asked to provide demographic and work role details. They were invited to identify a commissioning decision they had recently taken part in and to answer questions regarding the size and nature of that decision. Commissioners might work as individuals but more usually would be reporting on decisions taken as part of a group.
In addition, participants were asked to what extent various sources of evidence were important and used in the decision-making process. These were categorised as 'very important', 'quite important' or of 'limited importance', 'not important', 'not used'. The types of evidence were classified into two categories: empirical/ external (eg, clinical guidelines) and practical/internal (expert advice from colleagues) based on the Weatherly scale, ${ }^{10}$ as shown in online supplementary appendix 2 .

\section{Data collection}

A sample size calculation was undertaken to allow us to detect a $10-15 \%$ difference in proportions (with $80 \%$ power and a $95 \%$ CI) in response to professional work roles (clinically vs non-clinically qualified commissioners). This indicated that approximately 300 respondents would be required. Following discussion with the study sites, we estimated that we would need to invite approximately $450-500$ potential participants and 10-15 PCTs, excluding pilot sites.

Stratified random sampling of 15 PCTs from a total of 143 eligible sites was conducted. Contact details of all staff employed at NHS grade 7 or above who were involved in commissioning decision-making were obtained from each identified PCT. This included staff from Departments of Public Health, Finance, Purchasing, Commissioning, Contract monitoring and Information Services as well as the executive team.

Participants were given information sheets and details of how to participate. They could complete the survey via face-to-face meetings held at their office or by email using an online electronic questionnaire software host. Four additional reminders were sent to non-responders at two-weekly intervals. Questionnaires completed both manually and electronically were anonymised.

\section{Data analysis}

Logistic regression analysis was undertaken using SPSS. Responses were dichotomised so that the dependent variable was binary: whether the median score assigned to questions about the importance of sources of empirical evidence was 'very/quite' important, or of 'limited importance/not important/not used'. Missing data for individual evidence sources were not included in calculation of the median for each respondent.

Backwards stepwise logistic regression analyses were used with the following predictors: age, gender, years' experience in NHS commissioning, whether the respondent was a qualified medical doctor, pay (dichotomised to grade $7 / 8 \mathrm{a}$ or grade $8 \mathrm{~b} / 8 \mathrm{c} / 8 \mathrm{~d} / 9$ or above) and work role (Public Health, Commissioning and Contracts, Finance or other).

All six predictors were entered in the model and assessed at each step against criteria to remain in the model $(\mathrm{p}<0.1)$. The analysis stopped when all predictors remaining in the model met the criteria. Model evaluation, goodness of fit and validation of predicted probabilities were calculated using the likelihood ratio test, 
the Hosmer-Lemeshow test and the c-statistic. The Wald statistic was used to determine whether each independent variable was a significant contributor.

We obtained ethics approval from the Warwickshire Research Ethics Committee (09/H1211/63) and local ethics and research governance approval for each PCT included in the study.

\section{RESULTS}

\section{Participant characteristics}

Fifteen PCTs were invited to participate in the study. In the first wave six PCTs accepted and were randomised by strata. In the second wave of recruitment 5 more PCTs accepted giving a final total of 11 PCTs. Participating PCTs were representative of all PCTs in England in relation to demographic characteristics, general practitioner list size and Care Quality Commission (CQC) ratings. In total, the survey was circulated to 440 individuals across the 11 PCTs and 345 responded (a response rate of $78 \%$ ). The lowest PCT response rate was $72 \%$.

The median age band of individual participants was $45-54$ years and $63 \%$ were female, almost exactly replicating the characteristics of the NHS Information Centre Infrastructure Support Staff Statistics in England. ${ }^{10}$ Thirty-one percent $(\mathrm{n}=107)$ of respondents were clinically qualified (medical, nursing or allied health professionals), although only $1 \%(n=3)$ were currently also primarily employed in a clinical setting. Sixty-nine percent $(\mathrm{n}=239)$ held a higher degree (Masters, NHS management qualification, clinical qualification or a $\mathrm{PhD}$ ). The largest single group of respondents $(43 \%, \mathrm{n}=149)$ were working in Commissioning and Contracts roles, with 33\% $(\mathrm{n}=114)$ working in Public Health roles. Seven percent $(n=24)$ of respondents worked in the Finance department and $15 \%$ of respondents $(n=52)$ were spread across Other Commissioning Settings. Forty-seven percent of participants (163) had 5 years' or less experience in healthcare commissioning. An employee's salary ranged from $£ 34000$ to over $£ 100000$, with the median salary at approximately $£ 45000-£ 55000$, equivalent to Band $8 \mathrm{~b}$ in NHS pay scales.

\section{Decision-making characteristics}

The most common type of decision reported was 'changing the organisation or design of a particular service' and this was selected by 189 participants (55\%). This was followed by a 'major decision on strategic direction' (24\%) and Individual Funding Requests (IFRs) (9\%). The remaining $12 \%$ did not identify a relevant decision and were excluded from subsequent analysis. The specialty or service area within which the decision took place varied considerably. The largest single category of decisions affected between 1000 and 100000 people $(47 \%)$, and these were estimated to cost between $£ 100000$ and $£ 1000000(40 \%)$.

Figure 1 shows the reported use of different types of evidence in the decisions described. It presents the data as percentages to demonstrate the variation in the importance of the 17 factors that were assessed. The 10 empirical evidence factors (based on the Weatherly scale ${ }^{11}$ ) were consistently scored as being of 'limited importance, not important or not used' as compared to the practical evidence factors (based on a work
Figure 1 Responses to questions on use of evidence sources. Reproduced with permission from Swan. ${ }^{10}$

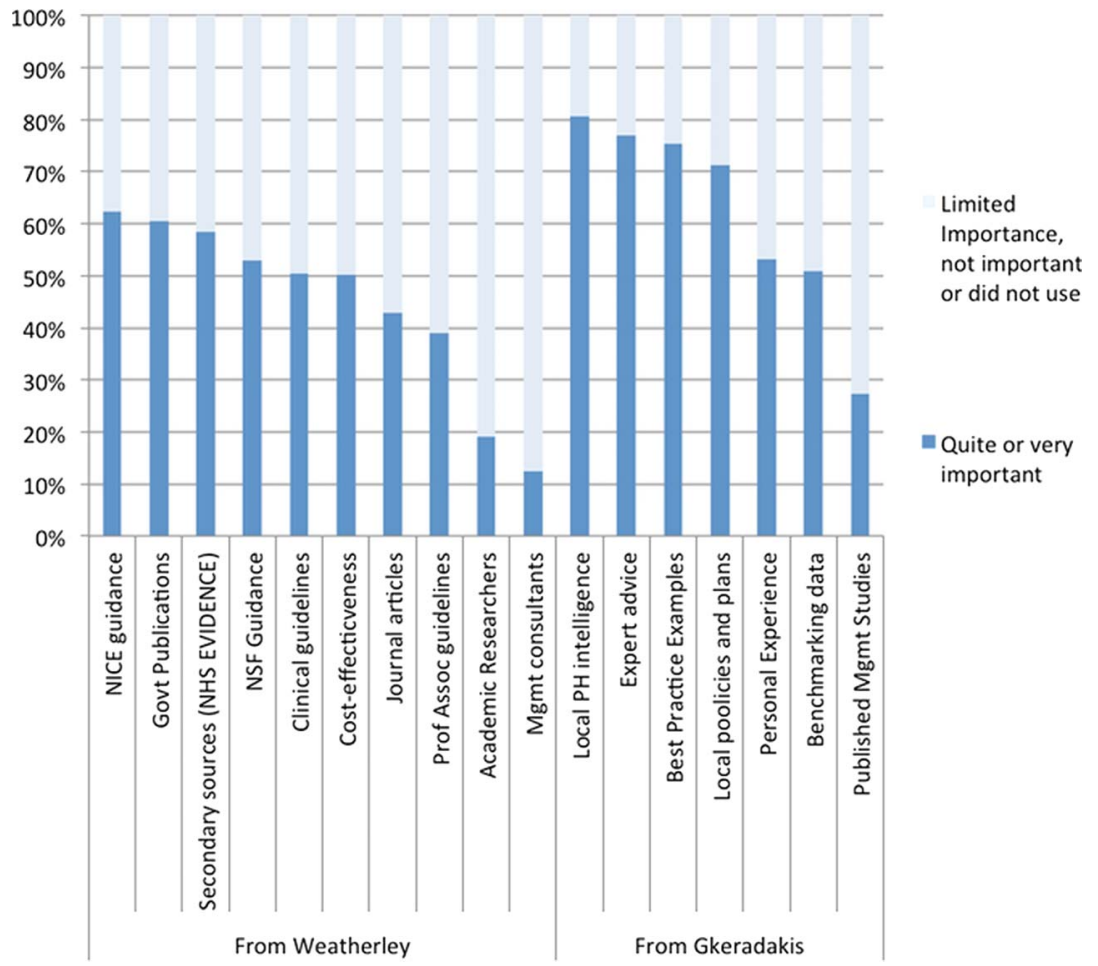


undertaken by Gkeradakis et $\left.a l^{7}\right)$. Clinical guidelines, cost-effectiveness and benchmarking data achieved only $50 \%$ importance rating.

\section{Use and importance of empirical evidence}

Logistic regression analysis (table 1) revealed that the significant predictors of the importance assigned to use of empirical evidence were gender and work role. Compared to their Public Health colleagues, respondents working in other departments were less likely to report use of empirical evidence (commissioning and contracts (OR $0.32,95 \%$ CI 0.18 to 0.57 ); finance (OR $0.19,95 \%$ CI 0.05 to 0.78 ); other departments (OR 0.35, $95 \%$ CI 0.17 to 0.71$)$ ). Female respondents were more likely to report a higher importance of empirical evidence in their commissioning decisions, in comparison to their male counterparts (OR $1.895 \%$ CI 1.01 to 3.1).

The model was a good fit to the data (Hosmer and Lemeshow $\left.\chi^{2}(4)=1.1, p=0.9\right)$, and model predictions showed reasonable agreement with actual outcomes (c-statistic $=0.65)$. No evidence was found that clinical training was associated with a greater likelihood of use of empirical evidence.

\section{Use and importance of practical evidence}

Logistic regression analysis (table 2) showed that the only significant predictor of the importance assigned to the use of practical evidence was pay grade. Those participants at NHS pay grade $8 \mathrm{~b}$ or above were more likely to report higher importance of practical evidence in their commissioning decisions (OR 2.7 95\% CI 1.4 to 5.3). Compared to their Public Health colleagues, respondents working in Commissioning and Contracts departments showed a trend towards being more likely to report use of practical evidence (OR $1.8,95 \% \mathrm{CI} 0.8$ to 4.1 , although this finding was not significant. The

Table 1 Logistic regression analysis of the importance assigned to empirical evidence (median score of quite/very important in comparison to limited importance/not important/ did not use)

\begin{tabular}{|c|c|c|c|}
\hline \multirow{3}{*}{$\begin{array}{l}\text { Variable } \\
\text { Female gender } \\
\text { Role }\end{array}$} & \multicolumn{2}{|c|}{ OR (95\% Cl) } & \multirow{2}{*}{$\frac{\text { Significance }}{0.047}$} \\
\hline & 1.779 & (1.007 to 3.144$)$ & \\
\hline & & & $<0.005$ \\
\hline $\begin{array}{l}\text { Role } \\
\text { (commissioning } \\
\text { and contracts) }\end{array}$ & 0.320 & (0.180 to 0.570$)$ & $<0.005$ \\
\hline Role (finance) & 0.194 & (0.048 to 0.779$)$ & 0.21 \\
\hline Role (other) & 0.349 & (0.171 to 0.713 ) & 0.04 \\
\hline Constant & 1.317 & & 0.337 \\
\hline \multicolumn{4}{|c|}{$\begin{array}{l}\text { Reference category for role is Public Health. Variable(s) entered on } \\
\text { step 1: gender, age, years' experience of NHS commissioning, } \\
\text { work role, pay and whether the respondent has any medical } \\
\text { qualifications. Likelihood ratio test } \chi^{2}(2)=25.3, p<0.0005 \text {, Cox and } \\
\text { Snell } R^{2}=0.09 \text {, Nagelkerke } R^{2}=0.12 \text {, Hosmer and Lemeshow } \chi^{2}(4) \\
=1.1, p=0.9, \text { c-statistic }=0.65 \text {. }\end{array}$} \\
\hline
\end{tabular}

Table 2 Logistic regression analysis of the importance assigned to practical evidence (median score of quite/very important in comparison to limited importance/not important/ did not use)

\begin{tabular}{llll}
\hline Variable & OR $(95 \%$ CI) & Significance \\
\hline $\begin{array}{l}\text { Female gender } \\
\text { Role }\end{array}$ & 1.808 & $(0.909$ to 3.595$)$ & 0.092 \\
Role & 1.82 & $(0.815$ to 4.067$)$ & 0.004 \\
$\begin{array}{l}\text { (commissioning } \\
\text { and contracts) }\end{array}$ & & & 0.144 \\
$\begin{array}{l}\text { Role (finance) } \\
\text { Role (other) }\end{array}$ & 0.492 & $(0.127$ to 1.899$)$ & 0.303 \\
$\begin{array}{l}\text { Pay grade 8b or } \\
\text { above }\end{array}$ & 2.708 & $(1.37$ to 5.342) & 0.004 \\
Constant & 1.843 & & 0.174 to 0.879) \\
\hline
\end{tabular}

Reference category for role is Public Health. Reference category for pay grade is band 7 or 8 a. Variable(s) entered on step 1: gender, age, years' experience of NHS commissioning, work role, pay and whether the respondent has any medical qualifications. Likelihood ratio test $\chi^{2}(5)=22.8, p<0.0005$, Cox and Snell $R^{2}=0.08$,

Nagelkerke $R^{2}=0.13$, Hosmer and Lemeshow $\chi^{2}(7)=6.5, p=0.5$, c-statistic $=0.68$.

model was a good fit to the data (Hosmer and Lemeshow $\chi 2(7)=6.5, \mathrm{p}=0.5)$, and model predictions showed reasonable agreement with actual outcomes (c-statistic $=0.68$ ). No evidence was found that clinical training was associated with a greater likelihood of use of practical evidence.

\section{DISCUSSION}

We undertook a cross-sectional survey in a representative sample of 345 commissioners in England to examine the use of empirical and practical evidence in commissioning decisions in the NHS. The aim of the research was to determine the types of evidence local commissioners of health services use in practice and to investigate whether the characteristics of the decision-maker and the decision size significantly influence the decision-making process.

The extent to which empirical evidence is used for commissioning decision-making in the NHS varied according to different types of commissioners. Female commissioners and those specialised in Public Health were more likely than those working in commissioning and contracts, finance or other job roles to report using empirical evidence in commissioning decisions.

Those at a higher pay scale were more likely than those in other roles to assign a greater importance to the use of practical evidence. Those with clinical training did not appear more likely to use either empirical evidence.

\section{Strengths and limitations}

Considerable effort was made to obtain and retain participation from PCTs. A 78\% response rate in participating PCTs was achieved and the resulting sample was 
representative of relevant NHS staff. Eleven PCTs were included in the final sample from an original target of fifteen. Refusal to participate was typically made on the grounds of extensive staff change and structural reorganisation occurring as a result of nationally driven organisational changes in PCTs and the NHS at this time.

There was substantial variability in the organisational structures of participating PCTs. Because there was no register of PCT staff, we asked PCTs to provide their own lists of relevant participants. This was not independently verifiable, but we have no reason to believe that staff involved in commissioning were systematically omitted from the lists. We designed our own questions, rooted in an extensive qualitative investigation, to capture the types of evidence commissioners were using; these were fully piloted, but formal assessments of their validity and reliability were not undertaken.

The findings may be subject to recall bias, although this should not differentially affect types of staff and the evidence sources that they used. A more serious bias might be social desirability bias where self-reporting of greater or lesser use of either empirical or practical evidence might be reported than in fact occurred. Although we are not able to measure the presence of this, immediate anonymisation of the questionnaires completed at the PCT sites and the reassurances of anonymity given in relation to electronic completion of the questionnaire should have reduced the likelihood of this type of bias. The design of this study did not allow us to follow up on decisions to investigate their outcomes or determine if there was an overlap between the decisions described by individual respondents.

\section{Implications for the changing NHS}

Previous research has identified several sources of external empirical evidence which are important in decisionmaking for commissioning in healthcare, including NICE guidance, National Service Frameworks and secondary research. This research further suggests that practical sources, such as local public health intelligence, expert advice and benchmarking data, are important and are actively being used by commissioners working in the NHS.

It was interesting to discover that apparently $50 \%$ of healthcare decisions made by commissioners in our study were not based on clinical evidence, and $50 \%$ were not based on the consideration of cost-effectiveness of the various decision options. This contradicts the evidencebased decision-making approach which aims to resolve uncertainty about which treatments, procedure and interventions represent the best quality care for patients and which offer the best value for money for the NHS.

There is an extensive and diverse discourse on the need for 'evidence-based' policy and commissioning. ${ }^{4}-7$ Critical to this debate is a shared definition of "evidence'. We have found reports of empirical and practical evidence being used differently by different professional groups in real commissioning decisions undertaken in PCT settings. Those trained in Public Health and women involved in commissioning appeared more likely to use external empirical evidence in decisions than others working in commissioning. Those at higher pay scales were more likely to use practical evidence. This could result in variations in the outcomes of the decision-making processes according to the professional group and employment status of the collective decision-makers. This has significant implications for selection of individuals in the new CCGs.

Compared to PCTs, CCGs are designed to have a higher senior representation of primary care practitioners at board level, but will also have more limited representation of those with a Public Health background. Public Health support will be changing as the specialty move away from the NHS into local authorities.

From our findings, these changes are likely to affect the types of evidence which these organisations will use in their commissioning decisions. New CCGs will have to recognise the need for a variety of different sources of inputs and evidence in their commissioning plans and ensure that they have the appropriate mix of advice and support to allow them to make the best decision for their populations.

\section{CONCLUSIONS}

Variation exists in the sources of evidence used for decision-making in healthcare commissioning in the NHS in England. Professional background, seniority and gender had a significant impact on the choice of evidence used for decision-making across the NHS PCTs included in the study. Individuals trained in Public Health appeared more likely to use external empirical evidence and those at higher pay scales were more likely to use practical evidence when making commissioning decisions. New Clinical Commissioning Groups will need a variety of different professional experts and sources of evidence to ensure that effective commissioning decisions are made for their populations.

Contributors STP, EG and PM carried out data collection. STP completed the results analysis and writing of the Method, Results and Discussion sections. AC was the editor of the paper. AC, JS, DN and JP performed liaison with the Trusts and oversaw the project. STP and PM carried out the design and liaison for data collection. AC, STP and AG contributed to the writing of the Introduction section and editing of comments on the whole paper. All authors have approved the final published paper.

Funding This project was funded by the National Institute for Health Services and Delivery Research programme (project number 08/1808/244).

Competing interests None.

Ethics approval Warwickshire Research Ethics Committee (09/H1211/63) and local ethics and research governance approval for each PCT included in the study.

Provenance and peer review Not commissioned; externally peer reviewed.

Data sharing statement No additional data were available.

\section{REFERENCES}

1. Department of Health. Equity and excellence: liberating the NHS. Department of Health, 2010.

2. Smith J, Dixon J, Maya N, et al. Practice based commissioning: applying the research evidence. BMJ 2005;331:1397-9. 
3. Weiss $\mathrm{CH}$. Many meanings of research utilization. Public Adm Rev 1979;39:426-31.

4. Davies H, Nutley S, Walter I. Why 'knowledge transfer' is misconceivedfor applied social research. $J$ Health Serv Res Policy 2008;13:188-90.

5. Walshe K, Rundall TG. Evidence-based Management: from theory to practice in health care. Milbank Q 2001;79:429-57.

6. Gabbay J, Le May A. Practice-based evidence for healthcare: clinical mindlines. Routledge, 2010.

7. Gkeredakis E, Swan J, Powell J, et al. Mind the gap: understanding utilisation of evidence and policy in health care management practice. J Health Organ Manag 2011;25:298-314.
8. Tsoukas $\mathrm{H}$, Vladimirou $\mathrm{E}$. What is organizational knowledge? J Manag Stud [proceedings paper] 2001;38:973-93.

9. Swan J, Clarke A, Nicolini D, et al. Evidence in Management Decisions (EMD)—Advancing Knowledge Utilization in Healthcare Management. NIHR Health Services and Delivery Programme; 2012, Final Report.

10. The NHS Information Centre. NHS hospital and community health services non medical workforce census. London: The Health and Social Care Information Centre, 2010.

11. Weatherly $H$, Drummond M, Smith D. Using evidence in the development of local health policies. Int $J$ Technol Assess Healthcare. 2002;18:771-81. 